\title{
The Utility of Online Resources in Times of COVID-19: A Mexican Medical Student Point of View
}

Aldo Mijail Pacheco Carrillo.'

\section{The Experience}

It has been four months since November 2019 when the SARS-COV-2 outbreak started in Wuhan, China. At the beginning there were medical students who did not believe that the disease would reach Latin America and that news was overstated, as of right now coronavirus disease is a particular burden on the health care systems of many countries including Mexico, mainly due to the lack of resources in public hospitals. It also impacts on the medical education of the country because all universities commanded their students to stay home so the government could handle the situation, firstly for 3 weeks, but it seems that the time of quarantine might be more. Meanwhile many students and professors are still battling to do online lectures because, in contrast to the U.S.A. education system, ${ }^{1}$ here in Mexico most of the lectures at university require the student in the classroom, that is why teachers are not used to web lessons.

I have noticed that many of my classmates did not really know the existence of online courses and the quality they may have, it occurs the same with web workshops and other certificate offering resources that many people, including myself, have used to gain extracurricular knowledge in matters of research, clinical applicated knowledge and more. So far in a week I have taken a course about antibiotics provided free by Stanford university, another one about how to use Mendeley by Elsevier online campus and one more course about important information about covid-19 by the Mexican Institute of Social Security, while I attending my regular lectures using the app Zoom to chat with my professors and classmates. I must admit that the quality of online regular lectures are not the same as the presential lectures I get at the university. One out of ten times the internet connection will make very loud interference noise causing the online reunion to end prematurely. However, I see more advantages than disadvantages, for example, I take most of the classes at my desk or bed, to be honest, I feel comfortable doing it. I also have more time to exercise at home and to cook healthy food, on the other hand, the only bad thing I see is the risk of social isolation leading to depression. ${ }^{2}$ In my case, I stay with my family and keep contact with my friends by using social media, but for the people living alone the situation could be dangerous. Additionally, I have noticed that many of my friends are spending more time in social media and streaming platforms instead of investing time exploring online academic resources. Maybe because they don't know of their existence.
How are online resources a great window of learning opportunity? There are plenty of online courses and many of them allow you to fulfill their objectives in a very generous space of time. For example, I took a course about how to write a paper in English with twenty hours of lectures through 8 weeks. Besides the time efficiency, a student can learn something he hasn't seen yet but he will soon, turning the online courses into a flipped classroom that has been proved to generate strong positive perceptions on evaluation surveys and benefit the student knowledge and learning process. ${ }^{3}$

Are online resources proven to be beneficial to students?

Depending on the resource, it has been proved that online platforms providing study tools have a positive effect as long as the student participates actively (answering questions and taking notes ). ${ }^{4}$ Further, open online courses have reported to have a huge potential improving soft-skills and research skills, ${ }^{5}$ and although they cannot replace the traditional model, they can be added as a complement and a way to encourage self-directed learning skills. ${ }^{6}$ A previous study demonstrated that touch screen device apps improve information retrieval and conceptual understanding.?

Are online courses and study platforms valid options in times of COVID-19? Considering the long time, we will not be able to go out, the short answer is yes. Online resources have shown benefits for learners in terms of engagement, convenience, attainment and enjoyment. ${ }^{8}$ I think they are comfortable as well as they generate compromise. In fact, they could be entertaining. Despite the limitations, I think they represent an important tool for medical students around the world.

In summary, we live in an unprecedented time, the covid19 outbreak has paralyzed the world including medical students. They remain in quarantine in the hope that the pandemic will end. The Latin America countries are particularly affected by their lack of resources and the time when medical students return to the universities is lengthening. Meanwhile the use of online platforms to resume the classes and the variety of online courses to complement the learning seems promising and should be more widely disseminated.

\footnotetext{
Medical Student, Autonomous University of Yucatan, Mexico.
}

About the Author: Aldo Mijail Pacheco Carrillo is currently a 5th-year medical student of the Faculty of Medicine at Autonomous University of Yucatan, Mérida, México, of a seven-year program. He is also an active member of AMMEF-IFMSA. 


\section{Experience}

\section{References}

1. Rose S. Medical Student Education in the Time of COVID-19. JAMA.2020 Mar 31 [Epub ahead of print]

2. Hämmig 0. Correction: Health risks associated with social isolation in general and in young, middle and old age. PLoS One. 2019 Aug 29;14(8):e0222124.

3. Ramnanan C, Pound L. Advances in medical education and practice: student perceptions of the flipped classroom. Adv Med Educ Pract. 2017 Jan 13;8:63-73.

4. Bientzle M, Hircin E, Kimmerle J, Knipfer C, Smeets R, Gaudin R, et al. Association of Online Learning Behavior and Learning Outcomes for Medical Students: LargeScale Usage Data Analysis. JMIR Med Educ. 2019 Aug 21;5(2):e13529.

5. Rowe M, Osadnik C, Pritchard S, Maloney S. These may not be the courses you are seeking: a systematic review of open online courses in health professions education. BMC Med Educ. 2019 Sep 14;19(1):356.
6. Mahajan R, Gupta P, Singh T. Massive Open Online Courses: Concept and Implications. Indian Pediatr. 2019 Jun 15;56(6):489-495.

7. Morris N, Lambe J, Ciccone J, Swinnerton B. Mobile technology: students perceived benefits of apps for learning neuroanatomy. I Comput Assist Lear. 2016 Apr;32(5):430-442.

8. Mello L. Fostering postgraduate student engagement: online resources supporting self-directed learning in a diverse cohort. Research in Learning Technology. 2016;24(1):29366.

\section{Acknowledgments}

None

Conflict of Interest Statement at Funding

The Authors have no funding, financial relationships or conflicts of interest to disclose.

Author Contributions

Conceptualization: AMPC. Methodology: AMPC. Investigation: AMPC. Writing - Original Draft: AMPC. Writing - Review \& Editing: AMPC. Visualization: AMPC.

Cite as:

Pacheco Carrillo AM. The Utility of Online Resources in Times of COVID-19: A Mexican Medical Student Point of View. Int J Med Students. 2020 Jan-Apr;8(1):5859. 